American Journal of Agricultural and Biological Sciences 3 (1): 358-363, 2008

ISSN 1557-4989

(C) 2008 Science Publications

\title{
Factors Affecting Agricultural Land Fragmentation in Iran: A Case Study of Ramjerd Sub District in Fars Province
}

\author{
${ }^{1}$ Khalil Kalantari and ${ }^{2}$ Gholamhossein Abdollahzadeh \\ Faculty of Agricultural Economics and Development, Agricultural \\ and Natural Resources Campus, University of Tehran, Karaj, Iran
}

\begin{abstract}
The objective of this study was to examine the factors influencing fragmentation of landholdings commonly regarded as a major obstacle to agricultural development in Iran. A sample of farmers was selected and household and village-level data from 12 villages of Ramjerd sub district in Fars province were used to test these factors empirically. Required data were collected by questionnaire from 151 farmers who were selected through a stratified random sampling design from 12 villages of Ramjerd sub District of Marvdasht County in South of Iran. The findings indicated that the fragmentation is the result of several processes (including social, culture, economic, physical and operational processes), working either together or independently. The influences of these factors on land fragmentation were calculated by linear regression model. Results indicated that household average annual income, per capita arable land, size of land rented by household, labour force of household, family size, number of crop planted by household and size of land rented out, contributing to land fragmentation.
\end{abstract}

Keywords: Land fragmentation, land consolidation, land size, agricultural development

\section{INTRODUCTION}

Agriculture is one of the most important economic sectors of Iran. Its contribution to GDP is approximately 27 percent, in employment is 23 percent (employed 3.5 million people) and its share in non-oil exports is 24 percent. In recent years, the agriculture sector has shown a significant development potential. It can provide 85 percent of Iran's food needs and 90 percent of the raw material needs of its food processing industries. Therefore, the agriculture sector has a most important place in the macroeconomics at $\operatorname{Iran}^{[13]}$. Before land reform in the 1960s, the agriculture sector, in addition to meeting the domestic food requirement, contributed to exports. Agricultural growth depends greatly on productivity improvement. Production resources can be increased through infrastructural development, appropriate technology, new farming methods, and farm management improvement. Countries with traditional agricultural structures face small and fragmented plots, cultivation is carried on to non-geometric small-scale plots which limit application of farm machinery, mechanization development, and putting to practice new cultivation methods. Therefore, application of modern technology, aimed at increasing yield and reducing production costs, has a direct relationship with land consolidation and optimum size of cultivation plots.

Many studies prove this assertion. For example, in irrigated wheat, one percent of increase in farm size causes a 0.4 percent decrease in cost, and one percent decrease in fragmentation causes a 0.44 percent decrease of $\operatorname{costs}^{[1]}$. Another study shows that land consolidation causes a 20 percent yield increase ${ }^{[6]}$. It is true that in traditional systems, fragmentation had some advantages ${ }^{[17]}$, but under an agricultural renovation condition, fragmentation is a serious limiting factor. It causes high increase in costs, and makes the productivity improvement activities uneconomical. Therefore, consolidation of fragmented plots of lands for achieving optimum size and shape of farmland, directly affects productivity. The experiences of different countries confirm this claim. In view of these considerations, numerous land consolidation and land reform policies have been implemented to reduce fragmentation in European countries like the Netherlands and France, in African countries like Kenya, Tanzania and Rwanda, and elsewhere ${ }^{[9]}$.

Small landholdings were well-adapted to Iran's agriculture sector. With increasing population pressure

Corresponding Author: Khalil Kalantari, Faculty of Agricultural Economics and Development, Agricultural and Natural Resources Campus, University of Tehran, Karaj, Iran 
and more efficient technology, they are coming under increasing strain. In the long run, they may be not adaptive at all. Therefore, for an economic crop production it is necessary to execute land consolidation programs that can provide appropriate living standards for farmers. According to some studies, the optimum farm size for economic crop production should be at least $12 \mathrm{ha}^{[16]}$. Because farmers with smallholdings are unable to take advantage of the new technology and were thus less productive ${ }^{[8]}$. The low productivity of small farms constrains sustainable crop production at regional and national levels. Summarizing these arguments, land fragmentation is considered as one of the major obstacles to achieve sustainable rural livelihoods, in Iran. Accordingly, the extensive arrays of smallholdings need to be restructured and consolidated. Although land fragmentation is a recognized problem in Iran, little empirical research has been done on its driving factors and their relative importance. A better understanding of the causes of land fragmentation in Iran is needed, especially now that the country is confronted with the challenge of agricultural modernization resulting from its entry into the World Trade Organization (WTO). New technologies are in urgent requirement to reduce the production costs and to improve farm households' wellbeing. This paper intends to examine the factors affecting on land fragmentation in Ramjerd sub district of Fars Province. Land Reform (1960s) processes in agricultural sector are the origin of land fragmentation, as will be discussed below. The paper is organized as follows. Literature review section briefly reviews available studies on the origins and causes of land fragmentation in various countries. In method section, an analytical framework is derived that will form the basis for the empirical analyses. The results of the regression analyses are presented and discussed in results section. The paper ends with conclusions.

Definition of land fragmentation: Farmland fragmentation has been defined in different ways. Some studies divided the various definitions in to two distinct senses: the subdivision of farm property into undersized units too small for rational exploitation; and the excessive separation and dispersion of the parcels forming parts of single farm ${ }^{[10]}$. The both are normally termed as morcellment and parcellement respectively. Fragmentation thus relates into two problems: farm size (in terms of land area) and concentration of parcels.

Causes of farmland fragmentation (FF): Various studies have examined land fragmentation in different countries and regions. The causes of FF listed in the literature can be divided into two broad categories. The first regarded fragmentation as a result of exogenous or so-called supply side factors. Apart from the natural restriction, other factors include (1) partial inheritance system or population pressure; (2) significant imperfections in the land market; and (3) the breakdown of common property system under the pressure of population growth ${ }^{[2,10,15]}$. It is logical to argue that partial inheritance leads to land fragmentation when land with similar quality is equally divided by heirs. While the land fragmentation in the case of existing incentive for consolidation was explained as imperfection of the land market by many authors ${ }^{[11]}$. The breakdown of common property systems in some African countries due to the pressure of population growth was studied by some researchers ${ }^{[4}$ $, 9,12]$.

The others argued that supply side explanations were not sufficient to explain fragmentation in many areas in which land fragmentation was not related to above factors. They argued that land fragmentation was a result of rational economic decision ${ }^{[3,7,12]}$. It assumed that private benefits of fragmentation exceeded its private costs, and the benefits mainly came from the risk reduction of fragmentation. Firstly, land fragmentation may be a perfect logical and sound response to soil and crop variations or to spreading the risk of climatic and other hazards. Small field tends to lessen the damage of soil erosion and protect crops in a severe climatic condition. Since crops have distinctive growth requirements, a diversification in agricultural production caused by land fragmentation may reduce risk in total agricultural production. This production diversification may also ease the seasonal labour bottleneck. Secondly, land fragmentation may be suitable for certain technological and natural conditions. Thirdly, the scattering land reduces the risk of total loss from drought, flood, fire and other natural disasters and price uncertainty and other changes in economic environment, by diversifying cropping mixtures across different growing conditions. This is particularly true when risk-spreading mechanisms, such as insurance, storage or credit, are not well developed.

Other studies indicated that high transaction costs in labour markets ${ }^{[5]}$ and failures in commodity market $^{[14]}$ were also responsible for the land fragmentation. An attempt was made to explain the land fragmentation in Medieval England, and argued that when transaction costs in labour markets is high, the fragmented land enabled farmers to better fulfill their seasonal labour requirements and consequently to get high output ${ }^{[5]}$. Some studies presented a model of land fragmentation in the case of lacking commodity market. 
They argued that when there is a missing market for the commodities, farmers tend to diversify their cropping mixture to satisfy their consumption, which will be best suited by fragmented land ${ }^{[14]}$. Indeed this is an extension of risk reduction examples. The different emphasizes in causes of fragmentation have a very strong practical implication. If fragmentation is a result of farmer's rational choice, we would assume that land consolidation would not be carried out unless conditions related to farmers' decision of cropping changed. If, however, land fragmentation is a result of supply side factors, land consolidation may have its benefits exceed its costs.

\section{MATERIALS AND METHODS}

This study is an applied research, which was carried out by survey method. The population consisted of 3500 farmers who farming in 12 villages of Ramjerd sub district in Fars province that selected 151 people from the different village by random sampling method. The questionnaire by interview method was used for data collection. The questionnaire covered six areas: economic characteristics such as average net annual income, share of income from off-farm employment, size of land rented out and in by household, social and cultural characteristics such as family size, percent of labour force per household, age, past record of farming, natural and farming characteristics such as: total land area in available, per capita arable land area, average plot size, number of crop planted by household, number of plots cultivated by household, and land use characteristics such as: average distance between farmland and main water source, average distance between farmland and village center, average distance between farmland and main road. Explanatory variables measured in this framework. Potential indicators were used to measuring land fragmentation are the number of plots, average plot size, average distance from plots to dwellings, and the so-called Simpson index. The Simpson in dex is defined as

$$
1-\frac{\sum_{i=1}^{i} A_{i}^{2}}{A^{2}}
$$

Where, $A_{i}$ is the area of plot $\mathrm{i}$ and $\mathrm{A}$ is the total land area.

The available data set contains information on the first two indicators; both will be used for analysis in this paper. So In this paper Fragmentation as dependent variables is measured by the number of land plots of a single farm-holding and the average plot size of farmholding. For the data analysis, apart from several descriptive methods such as, mean and standard deviation, stepwise multiple regression technique was also used.

\section{RESULTS AND DISCUSSION}

Some key characteristics of farmers' households are presented in Table 1. It provides simple summaries about the sample and the measures. The number of plots cultivated by a household ranges from 1 to 18 . The average is 8 plots per household while the average plot size varies from 0.13 to 2.48 ha, with an average of 0.72 ha. The family size equals 6.33 people, with about $59.10 \%$ of the household members on average, belonging to the labour force. The average size of land rented by household is 1.84 ha that is substantially larger than the average size of land rented out by household (0.88 ha). Considering the share of off-farm income of the households in the sample

Table 1: Descriptive statistics of variables used in the regression analyses

\begin{tabular}{lllll}
\hline variables & Mean & Standard deviation & Minimum & Maximum \\
\hline Number of plots cultivated by household & 8.00 & 4.12 & 1.00 & 18.00 \\
Average plot size (ha) & 0.72 & 0.53 & 0.13 & 2.48 \\
Family size (number of people in family) & 6.33 & 2.19 & 1.00 & 14.00 \\
Size of land rented in by household & 1.84 & 1.01 & 0.00 & 3.83 \\
Size of land rented out by household & 0.88 & 0.60 & 0.00 & 3.26 \\
Share of off-farm income (per cent) & 36.40 & 21.79 & 6.50 & 94.75 \\
Household average annual income (1000000 Rial) & 186.00 & 74.00 & 64.00 & 396.00 \\
farming experience (year) & 19.91 & 9.08 & 3.00 & 45.00 \\
Age of landholders & 41.72 & 12.08 & 19.00 & 71.00 \\
Number of crop planted by household & 4.02 & 1.96 & 1.00 & 9.00 \\
Total land area in available (ha) & 5.02 & 5.53 & 0.13 & 35.00 \\
Per capita arable land area (ha) & 1.96 & 1.08 & 0.21 & 5.55 \\
Labour force of household (per cent) & 59.10 & 22.43 & 7.02 & 98.50 \\
Average distance between farmland and main water source $(\mathrm{Km})$ & 27.54 & 12.11 & 6.65 & 58.33 \\
Average distance between farmland and village center & 10.34 & 4.17 & 1.00 & 22.00 \\
Average distance between farmland and main road $(\mathrm{Km})$ & 8.23 & 4.58 & 0.50 & 22.00
\end{tabular}


Am. J. Agril. \& Biol. Sci., 3 (1): 358-363, 2008

Table 2: Relative contribution (partial and model $\mathrm{R}^{2)}$ in predicting land fragmentation, F-value and multiple correlation coefficients by the stepwise procedure analysis

\begin{tabular}{|c|c|c|c|c|}
\hline Variable entered & $\mathrm{R}$ coefficient & Partial $\mathrm{R}^{2}$ & Model R2 & F value \\
\hline \multicolumn{5}{|l|}{ Dependent variable: Average plot size } \\
\hline Household average annual income & 0.605 & 0.366 & 0.366 & 124.78 \\
\hline Per capita arable land area & 0.729 & 0.165 & 0.531 & 130.21 \\
\hline Size of land rented in by household & 0.759 & 0.045 & 0.576 & 107.05 \\
\hline Labour force of household & 0.777 & 0.027 & 0.603 & 92.31 \\
\hline Family size & 0.787 & 0.016 & 0.620 & 80.16 \\
\hline Number of crop planted by household & 0.795 & 0.012 & 0.632 & 71.06 \\
\hline Size of land rented out by household & 0.799 & 0.007 & 0.639 & 62.91 \\
\hline \multicolumn{5}{|c|}{ Dependent variable: number of plots cultivated by household } \\
\hline Per capita arable land area & 0.750 & 0.562 & 0.562 & 442.59 \\
\hline Share of off-farm income & 0.787 & 0.057 & 0.620 & 323.54 \\
\hline Household average annual income & 0.801 & 0.022 & 0.642 & 255.61 \\
\hline Family size & 0.808 & 0.011 & 0.653 & 209.83 \\
\hline Labour force of household & 0.813 & 0.008 & 0.661 & 179.18 \\
\hline Number of crop planted by household & 0.815 & 0.004 & 0.664 & 153.73 \\
\hline
\end{tabular}

Table 3: Regression coefficient (B), t-value and probability (sig.) of the accepted variables that can be used to predict land fragmentation by the stepwise procedure

\begin{tabular}{|c|c|c|c|c|}
\hline Variables & Coefficient of regression (B) & Beta & T/value & Sig. \\
\hline \multicolumn{5}{|l|}{ Dependent variables: Average plot size } \\
\hline Constant & -0.319 & & -2.365 & 0.019 \\
\hline Household Average annual income & 0.201 & 0.287 & 5.435 & 0.000 \\
\hline Per capita arable land area & -0.092 & -0.189 & -2.831 & 0.005 \\
\hline Size of land rented in by household & 0.109 & 0.212 & 3.934 & 0.000 \\
\hline Labour force of household & 0.004 & 0.179 & 3.772 & 0.000 \\
\hline Family size & 0.030 & 0.125 & 2.722 & 0.007 \\
\hline Number of crop planted by household & 0.046 & 0.174 & 2.651 & 0.009 \\
\hline Size of land rented out by household & -0.078 & -0.091 & -2.071 & 0.040 \\
\hline \multicolumn{5}{|c|}{ Dependent variables: number of plots cultivated by household } \\
\hline Constant & 2.767 & & 2.082 & 0.039 \\
\hline Per capita arable land area & 2.383 & 0.419 & 7.403 & 0.000 \\
\hline Share of off-farm income & -0.090 & -0.321 & -6.765 & 0.000 \\
\hline Household average annual income & 0.958 & 0.116 & 3.225 & 0.002 \\
\hline Family size & 0.303 & 0.109 & 3.230 & 0.002 \\
\hline Labour force of household & 0.029 & 0.108 & 3.130 & 0.002 \\
\hline Number of crop planted by household & 0.32 & 0.104 & 2.13 & 0.03 \\
\hline
\end{tabular}

* and **: means that $\mathrm{r}$ is significant at $5 \%, 1 \%$ level of probability respectively

(mean value: $36.40 \%$ ) confirms that households that are heavily involved in off-farm employment are not included in the sample. But household average net annual income varies from 64 to 396 million Rials with average 186 million Rials, (US. \$ 20000) Farmer's experience in agricultural activities were ranged from 3 to 45 years (19.91 years, on average) while average of ages of them was 41.72 years and ranged between 19 to 71 years. According to the results, number of crop planted by farmer varies from 1 to 9 crops with average 4.02 that is characteristic of livelihood and no trade agriculture. Total land area in available for household is 5.02 ha, that 1.96 ha of them is arable. Information in respect of other variables, such as: average distance between farmland and main water source, village center and main road are presented in Table 1.

Stepwise multiple linear regressions: This section provides an empirical analysis between 2 dependent variables (1-average plot size and 2-number of plots cultivated by household) and some of the explanatory variables that were established in the previous sections. This procedure was used to determine the variable accounting for the majority of total land fragmentation indicators. Multiple linear regressions in a stepwise manner were used and one variable was added to the regression equation at each step. The added variable was the one which induced the greatest reduction in the error sum of squares.

It was also the variable which had the highest partial correlation with the dependent variable for fixed values of those variables already added. Moreover, it was the variable which had the highest $F$ value. Table 2 shows the data representing partial and cumulative R2 as well as the probability for the accepted limiting six explanatory variables in land fragmentation prediction. These variables for the first dependent variable (average plot size) are: the household average annual 
income $(36.6 \%)$, per capita arable land area (16.5\%), size of land rented in by household $(4.5 \%)$, labour force of household $(2.7 \%)$, family size (1.6\%), number of crop planted by household $(1.2 \%)$, and size of land rented out by household $(0.7 \%)$. The explained variables for the second dependent variable (number of plots cultivated by household) are: per capita arable land area $(56.2 \%)$, share of off-farm income $(5.7 \%)$, household average annual income $(2.2 \%)$, family size $(1.1 \%)$, labour force of household $(0.8 \%)$ and number of crop planted by household $(0.4 \%)$. According to the results, $63.9 \%$ of the total variation in average plot size and $66.4 \%$ of the total variation in number of plot cultivated by household could be attributed to these aforementioned variables. F-value are high enough to reject the null hypotheses that the variables cannot explain the variations in land fragmentation between the households in the sample. The other variables were not included in the analysis due to their low relative contributions. Regression coefficients for the accepted variables are shown in Table 3.

\section{CONCLUSION}

This study advances beyond previous research of land fragmentation in Iran by providing a more detailed analysis of the processes underlying land fragmentation and using available fixed rural socio-economic observation data from 12 villages in Fars province to obtain empirical estimates of the major factors that causative of land fragmentation in Iran. The results obtained for these 12 villages showed that farm household average annual income is an important determinant of both the number of plots and average plot size. The share of labour force members in a household also plays a role in land fragmentation, as expected from background section. Results showed that when the labour force shares increases by 1 unit, the number of plot change more than the average plot size (0.303 compare with 0.004). Regression outcomes indicated that off-farm income of household members plays a key role in number of plot so it can consider decreasing land fragmentation. The findings further indicate that land rental markets reduce average plot size. Because, land rented in by household increases average plot size, while land rented out by household decrease average plot size. Moreover these two variables do not have a significant impact on number of plot cultivated by household.

Households with many fragmented plots may use the land rental market to decrease the dispersion of their land and increase production efficiency. In other word, land renting in and out depends positively on land fragmentation. At the village level, number of crop planted by household as sign for traditional and livelihood agriculture plays an important role on land fragmentation. In this case, land fragmentation may be a perfect logical and sound response to soil and crop variations or to spreading the risk of climatic and other hazards. Small field tends to lessen the damage of soil erosion and protect crops in a severe climatic condition. Since crops have distinctive growth requirements, a diversification in agricultural production caused by land fragmentation may reduce risk in total agricultural production. Per capita arable land availability in a village is likely to be correlated with variation in land quality (soil types, water access, drainage conditions, road access, and so on), is one of the variables that has significant impact in two models. The regression results for land arable availability will therefore partly reflect the impact of variation in land quality on land fragmentation. The results show that an increase in land arable availability (and hence variation in land quality) causes a significant increase in the number of plots cultivated by household and a significant, but smaller, decline in the average plots size. Income from off-farm employment increase land fragmentation by improving the land rental market by households. The regression results support this. In addition, households with more people tend to cultivate more plots than households within the same village who has fewer people. This support hypothesis that partial inheritance system or population pressure causes land fragmentation. It is logical to argue that partial inheritance leads to land fragmentation when land with similar quality is equally divided by heirs. Thus land fragmentation in Iran is the result of several processes (social, cultural, economic, physical and operational processes) working either together or independently and is caused to a large extent by traditional and livelihood agriculture structure.

\section{ACKNOWLEDGMENT}

This study was based on a research project financially supported by University of Tehran, Iran, which is highly appreciated.

\section{REFERENCES}

1. Arsalanbod, M.R., 2000. Effect of Farm Smallness and Fragmentation of Productive Units on Production Costs: Case of Irrigated Wheat in West Azerbaijan. Agric. Econ. Dev. Quarterly J., 8 (2). 
2. Binns, B. O, 1950. The Consolidation of Fragmented Agricultural Holdings. FAO Agricultural Studies, 11.

3. Blarel, B., P. Hazell, F. Place, J. Quiggin, 1992. The Economics of Farm Fragmentation: Evidence from Ghana and Rwanda. World Bank Econ. Rev., 6 (20): 233-254.

4. Dahlman, C, 1980. The Open Field System and Beyond. Cambridge University Press.

5. Fenoaltea, S, 1976. Risk, Transaction Costs, and the Origin of Medieval Agric. Exploration in Econ. Hist., 13: 129-51.

6. Haidari, G.R, 1996. Land Consolidation and Agric. Dev. Iran. Agric. Econ. Dev. Q. J., 4 (1).

7. Johnson, O. E. G, 1970. A Note on the Econ. Fragmentation. Nigerian J. Econ. Soc. Stud., 12 (2): $175-84$

8. Karami, E, 1983. The Differential Characteristics of Farmers with Regard to Their Innovativeness in Fars Province, Iran. Iran Agric. Res., 2: 125-136.

9. King, R, 1977. Land Reform: a World Survey. Bell and Sons, London.
10. King, R. L., S. Burton, 1981. An Introduction to the Geography of Land Fragmentation and Consolidation. Occasional Paper 8, Leicester University Geography Department.

11. Lipton, M, 1968. The Theory of the Optimizing Peasant. Journal of Development Studies., 4 (3): 327-51

12. McPherson, M. F, 1982. Land Fragmentation; A Selected Literature Review. Development Discussion Paper, No. 141, Harvard Institute for International Dev., Harvard University.

13. Najafi, A, 1998. Chronological Changes in Agric. MOA. Tehran.

14. Netting, R, 1972. Of Men and Meadows: Strategies of Alpine Land Use. Anthropological Q., 45: 14557.

15. Quiggin, J, 1988. Scattered Landholdings in Common Property System. J. Econ. Behav. Org., 9 (2): 187-202

16. Soltani, G. R, 1978. Small Farm versus Large Farm Development in Iran. Indian J. Agric. Econ., 33: 94-102.

17. Taleb, M, 1987. Effective Factors on Land Fragmentation and Necessity of Farmholdings Land Consolidation. Geographic Training Growth J., 15. 